\title{
A cancer cell metalloprotease triad regulates the basement membrane transmigration program
}

\author{
Kevin Hotary, Xiao-Yan Li, Edward Allen, Susan L. Stevens, and Stephen J. Weiss ${ }^{1}$ \\ Division of Molecular Medicine and Genetics, Department of Internal Medicine, Life Sciences Institute, University of \\ Michigan, Ann Arbor, Michigan 48109, USA
}

\begin{abstract}
Carcinoma cells initiate the metastatic cascade by inserting invasive pseudopodia through breaches in the basement membrane (BM), a specialized barrier of cross-linked, extracellular matrix macromolecules that underlies epithelial cells and ensheaths blood vessels. While BM invasion is the sine qua non of the malignant phenotype, the molecular programs that underlie this process remain undefined. To identify genes that direct BM remodeling and transmigration, we coupled high-resolution electron microscopy with an ex vivo model of invasion that phenocopies the major steps observed during the transition of carcinoma in situ to frank malignancy. Herein, a triad of membrane-anchored proteases, termed membrane type-1, type-2, and type-3 metalloproteinases, are identified as the triggering agents that independently confer cancer cells with the ability to proteolytically efface the BM scaffolding, initiate the assembly of invasive pseudopodia, and propagate transmigration. These studies characterize the first series of gene products capable of orchestrating the entire BM remodeling program that distinguishes the carcinomatous phenotype.
\end{abstract}

[Keywords: Basement membrane; type IV collagen; matrix metalloproteinases; MT-MMPs; cancer; invasion]

Supplemental material is available at http://www.genesdev.org.

Received May 24, 2006; revised version accepted August 4, 2006.

In all forms of cancer, a hallmark of the malignant process is the acquisition of an invasive phenotype that allows neoplastic cells to penetrate the basement membrane (BM), a specialized form of extracellular matrix that underlies all epithelial cells and ensheaths blood vessels, nerves, and muscle as well as fat (Hanahan and Weinberg 2000; Kalluri 2003). Comprised of $>50$ distinct macromolecular components, the BM is a thin $(\sim 100 \mathrm{~nm}$ thick), but mechanically strong structure dominated by a scaffolding of cross-linked type IV collagen molecules cointertwined with a network of polymeric laminin (Kalluri 2003). Consistent with the critical role that BMs assume in regulating cell adhesion, migration, differentiation, and survival, developmental defects in its assembly or composition result in embryonically lethal phenotypes (Poschl et al. 2004). Nonetheless, BMs regularly undergo focal remodeling during normal growth and development in organisms ranging from Caenorhabditis elegans to mammals (Sherwood et al. 2005). While the molecular machinery that allows trafficking cells to disassemble and transmigrate BMs under controlled circumstances remains undefined, current evidence suggests that similar, if not identical, gene programs are

${ }^{1}$ Corresponding author.

E-MAIL SJWEISS@umich.edu; FAX (734) 647-7950.

Article published online ahead of print. Article and publication date are online at http://www.genesdev.org/cgi/doi/10.1101/gad.1451806. inappropriately marshalled by malignant cells in cancer (Friedl and Wolf 2003; Sherwood et al. 2005).

In vivo, BMs are stabilized by a structurally complex mix of covalent and noncovalent forces that coalesce the network of interacting molecules into a molecular sieve that assumes an effective pore size on the order of $50 \mathrm{~nm}$ (Abrams et al. 2000; Kalluri 2003; Than et al. 2005; Vanacore et al. 2005). As such, it has long been assumed that cancer cells would, by necessity, either mobilize their own proteolytic enzymes or recruit them from accessory cell populations (e.g., fibroblasts or leukocytes) in an effort to degrade key BM components as a prelude to invasion (Friedl and Wolf 2003). Indeed, in the in vivo setting, malignant cells can often be found in the act of inserting invasive pseudopodial-like extensions through the BM wall while establishing adhesive interactions with underlying stromal structures (Friedl and Wolf 2003). However, no single protease, or set of proteases, has yet been identified that can confer neoplastic cells with the ability to degrade or traverse intact BMs. Consistent with this theme, more recent studies have concluded that neoplastic cells may adopt amoeboid phenotypes to traffic across BM barriers by exerting physical and mechanical forces that distort matrix architecture by nonproteolytic means alone (Friedl and Wolf 2003; Evan-Ram and Yamada 2005).

In part, efforts to characterize the mechanisms direct- 
ing BM invasion have been stymied by difficulties inherent in recapitulating the dynamic interactions that define tumor cell-matrix interactions in the in vivo setting. To this end, we now define an ex vivo model wherein cancer cell-mediated BM disassembly and transmigration can be tracked visually by high-resolution electron microscopic techniques. Using this system, neoplastic cells are shown to irreversibly remodel intact BM barriers while activating a cell-autonomous invasion program that is directed by any one of three distinct, membrane-anchored metalloproteinases. The identification of a proteolytic triad that arms human cancer cells with the ability to transmigrate native BM barriers could have important implications for the design of a new generation of selective, therapeutic interventions operative at the cell-matrix interface.

\section{Results \\ Cancer cell-mediated BM perforation and transmigration}

BMs recovered intact from in vivo tissues (i.e., the peritoneum) or assembled in long-term, three-dimensional culture by immortalized epithelial cells appear as continuous and organized $~ 80-100-n m$-thick sheets of type IV collagen- and laminin- rich ECM (Fig. 1A). Gentle mechanical disruption of either BM construct allows for the direct visualization of the underlying stromal matrix that is dominated by interstitial collagen fibrils (Fig. 1A). To determine the BM-invasive potential of human cancer cell lines, tumor cells of either epithelial, mesenchymal, or neural crest origin were cultured atop denuded BMs. Following a 2-h incubation period, all tumor cells are tightly apposed to the exposed surface of the BM and come to lie within $100 \mathrm{~nm}$ or less of the underlying matrix (Fig. 1B). Over the course of an 8-d culture period, cancer cells begin to actively perforate the underlying $\mathrm{BM}$ within $24 \mathrm{~h}$ by extending microfilament-rich $\sim 0.8$ $\mu \mathrm{m}$ diameter invadopodia into the subjacent interstitium in a fashion that recapitulates the in vivo invasion program (Fig. 1B). Scanning electron micrographs of tumor cell-traversed BMs reveal a pockmarked landscape decorated with excavated pits in which the cable-like structure of the underlying stromal matrix can be observed (Fig. 1C). Cancer cell-mediated BM remodeling allows each of the cell lines studied access to underlying tissues (Fig. 1D) with similar results obtained when live peritoneal explants are used in place of the cell-free explant (data not shown).

\section{$B M$ transmigration is driven}

by a metalloproteinase-dependent process

Of the $>500$ proteases expressed in the mammalian genome, most can be categorized as members of either the serine-, aspartyl-, cysteinyl-, or metallo-proteinase families (Puente et al. 2003). In the presence of high concentrations of potent, broad-spectrum inhibitors used commonly to block serine-, aspartyl-, or cysteinyl-protein- ases (Hotary et al. 2003; Filippov et al. 2005), BM invasive activity is unaffected and all cancer cell lines examined efficiently transmigrate the ECM barrier (Fig. 2A).

A subgroup of metalloproteinases belonging to the matrix metalloproteinase (MMP) gene family are uniformly up-regulated in invasive carcinomas (Egeblad and Werb 2002; Kalluri 2003). In the presence of either a peptidomimetic MMP inhibitor (i.e., BB-94) or the endogenous MMP inhibitor, TIMP-2 (Hotary et al. 2003), cancer cell invasion is blocked completely over an 8 -d culture period (Fig. 2A) and recovered BMs are entirely defect free (Fig. 2B). Neither inhibitor affects cell proliferation or viability under these conditions (Hotary et al. 2003; Sabeh et al. 2004). Further, whereas type IV collagen degradation products are immunodetected in association with both the perforated BM and transmigrated carcinoma cells (Xu et al. 2001), type IV collagen maintains its native structure in the presence of BB-94 (Fig. 2C). While potential roles for MMPs in cancer cell invasion have been largely dismissed given the paucity of significant clinical responses (Coussens et al. 2002), tumor cell transmigration across intact BMs is no longer inhibited ex vivo (data not shown) when the BB-94 concentration is lowered 25-fold to levels similar to those obtained in the in vivo setting (Denis and Verweij 1997). Further, though carcinoma cells have been reported to adopt an amoeboid-like phenotype in order to negotiate ECM barriers by nonproteolytic processes (Friedl and Wolf 2003), none of the cancer cell populations studied are able to mount BM invasive activity in the presence of broadspectrum MMP inhibitors. Of note, however, neither BB94 nor TIMP-2 are able to block cancer cell invasion through a gel-like mixture of type IV collagen, laminin, and proteoglycan (i.e., Matrigel), an artificial matrix that does not assemble into the ordered, covalently crosslinked structure that characterizes the native BM (Fig. 2D; Kalluri 2003; Evan-Ram and Yamada 2005). Hence, while tumor cells may not require MMP activity to traverse BM-like barriers whose structural characteristics are defined by noncovalent forces, proteolytic systems must be engaged in order to penetrate the intact BM barrier.

\section{A subfamily of MT-MMPs confer BM invasive activity}

The MMP family encompasses a group of $>20$ secreted or membrane-anchored enzymes that alone, or in a combination, can degrade a multiplicity of ECM components (Egeblad and Werb 2002). However, no MMP has been shown to confer cells with the ability to traverse the intact BM with its multicomposite amalgam of type IV collagen, laminin, nidogen, and complex proteoglycans. To this end, we first sought to identify individual MMPs that might endow invasion-null COS cells with the BM degradative activities necessary to support transmigration.

Originally characterized as type IV collagenases, MMP-2 (gelatinase A) and MMP-9 (gelatinase B) have long been postulated to play a dominant role in BM- 

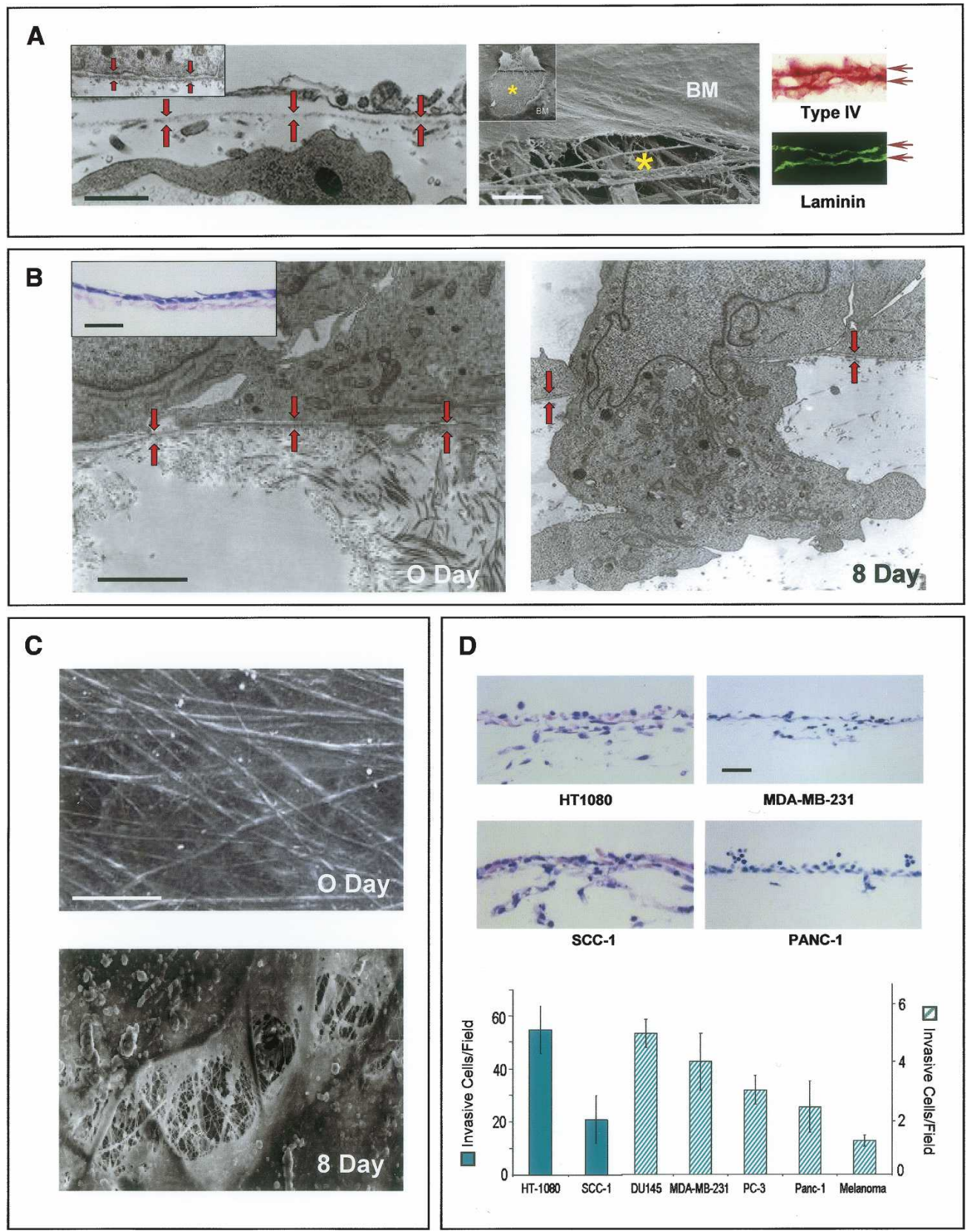

D
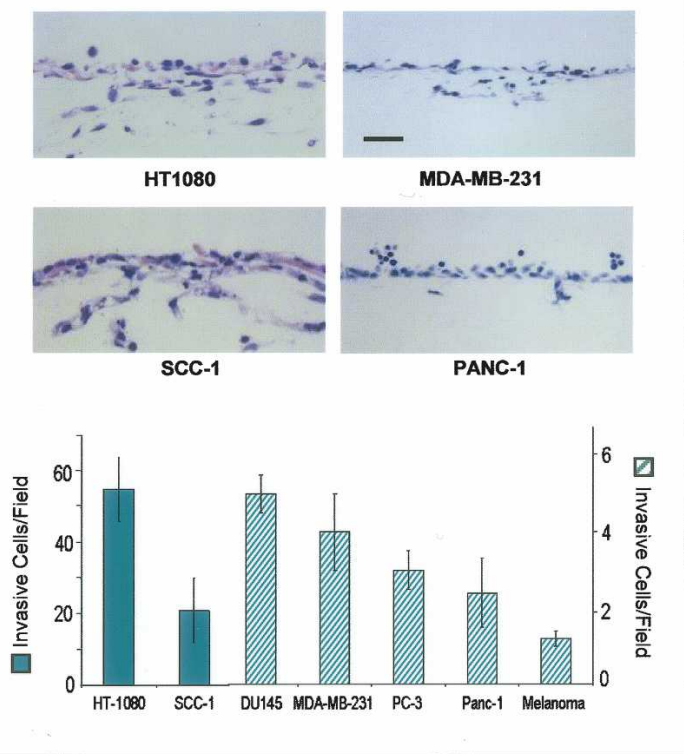

Figure 1. BM remodeling and transmigration by cancer cells. (A, left) Mesothelial BM (rat peritoneum) shown by TEM (red arrows demarcate BM). (Right) SEM (BM) highlights the sheet-like structure of the BM overlaying the stromal matrix (indicated by an asterisk). Immunostaining for type IV collagen and laminin (horizontal arrows) reveals the two BM layers (i.e., the upper and lower surfaces of the peritoneum are lined by BMs). Insets show the epithelial BM deposited by MDCK cells as visualized by TEM and SEM. Bars for TEM, SEM, and light micrographs are 1,20, and $100 \mu \mathrm{m}$, respectively. (B) MDA-MB-231 cells cultured atop the peritoneal BM at 0 and $8 \mathrm{~d}$ as assessed by TEM. BM (highlighted by red arrows) is breached by carcinoma cells after an 8 - $\mathrm{d}$ culture period. Inset shows an H\&E section of carcinoma cells at $0 \mathrm{~d}$. Bars for TEM and light micrographs are 1 and $200 \mu \mathrm{m}$, respectively. (C) SEM of peritoneal BM stripped of overlying MDA-MB-231 cancer cells immediately after plating $(0 \mathrm{~d})$, or after an 8-d culture period $(8 \mathrm{~d})$. Bar, $10 \mu \mathrm{m}$. $(D)$ Representative H\&E cross-sections of the peritoneum after an 8-d culture period. The number of invasive cells per field are quantified in H\&E-stained cross-sections with error bars indicating the standard error of mean of five or more experiments.

invasive events (Egeblad and Werb 2002; Kalluri 2003). Unexpectedly, COS cells engineered to express high levels of either MMP-2 or MMP-9 neither degraded nor invaded BM constructs (Fig. 3A). MMPs are, however, synthesized as latent enzymes that must undergo activation following either autocatalytic or protease-assisted processing (Egeblad and Werb 2002; Hotary et al. 2003). Hence, we considered the possibility that MMP-2 or MMP-9 might only catalyze BM remodeling if processed to their active forms. To this end, $M M P-2$ or $M M P-9$ was 
Hotary et al.
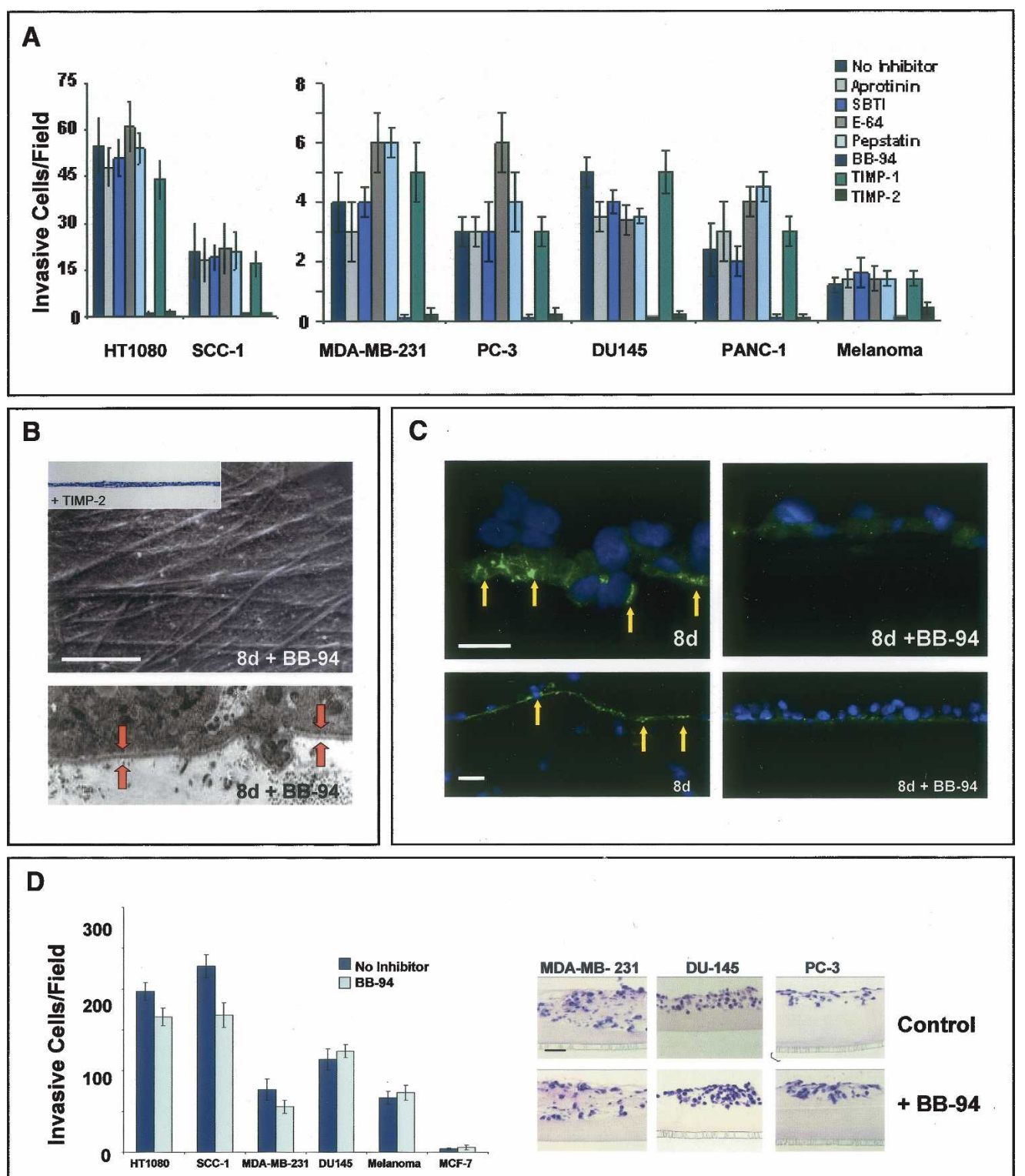

Figure 2. MMP-dependent BM invasion. (A) Cancer cells were cultured atop epithelial BMs for $8 \mathrm{~d}$ in the absence or presence of inhibitors directed against serine proteinases (aprotinin, soybean trypsin inhibitor; SBTI), cysteine proteinases (E-64), aspartyl proteinases (pepstatin) or MMPs (BB-94, TIMP-1, TIMP-2). Invasion is shown as the mean number of invasive cells per field \pm standard error of mean of five or more experiments. (B) SEM and TEM analyses of peritoneal BM stripped of overlying MDA-MB-231 cells following an 8-d culture period in the absence or presence of BB-94. (Bottom) The intact BM (which also completely surrounds the cellular projection from the basal surface) is bracketed by the red arrows in the TEM micrograph. Similar results were obtained with all of the cancer cell lines studied (data not shown). The inset shows the absence of invasion (as assessed in an H\&E-stained cross-section) when cancer cells are cultured in the presence of TIMP-2. Bar, $50 \mu \mathrm{m}$. (C) Degraded type IV collagen (green) is detected in peritoneal BMs breached by invasive MDA-MB-231 cells following an 8-d culture period (yellow arrows; the top and bottom images highlight the pattern of type IV collagen degradation at high and low magnification, respectively). In the presence of BB-94, MDAMB-231 cells neither degrade nor invade the underlying BM following an 8-d culture period. Cells are stained with DAPI (blue). Bars for SEM and light micrographs are 50 and $100 \mu \mathrm{m}$, respectively. $(D)$ Tumor cell invasion through Matrigel-coated filters was quantified following an 48-h culture period in the absence or presence of BB-94. The number of invasive cells per field is expressed as the mean \pm standard error of mean $(n=4)$. H\&E-stained cross-sections of tumor cell invasion through thick gels of Matrigel in the absence or presence of BB-94 following a 4-d culture period are shown to the right.

expressed as chimeric constructs wherein a proprotein convertase recognition motif (RXKR) was inserted between the pro- and catalytic domains of the MMP (Pei and Weiss 1995; Hotary et al. 2003). In this form, the enzymes undergo intracellular processing to fully active proteinases prior to their secretion (Pei and Weiss 1995; 

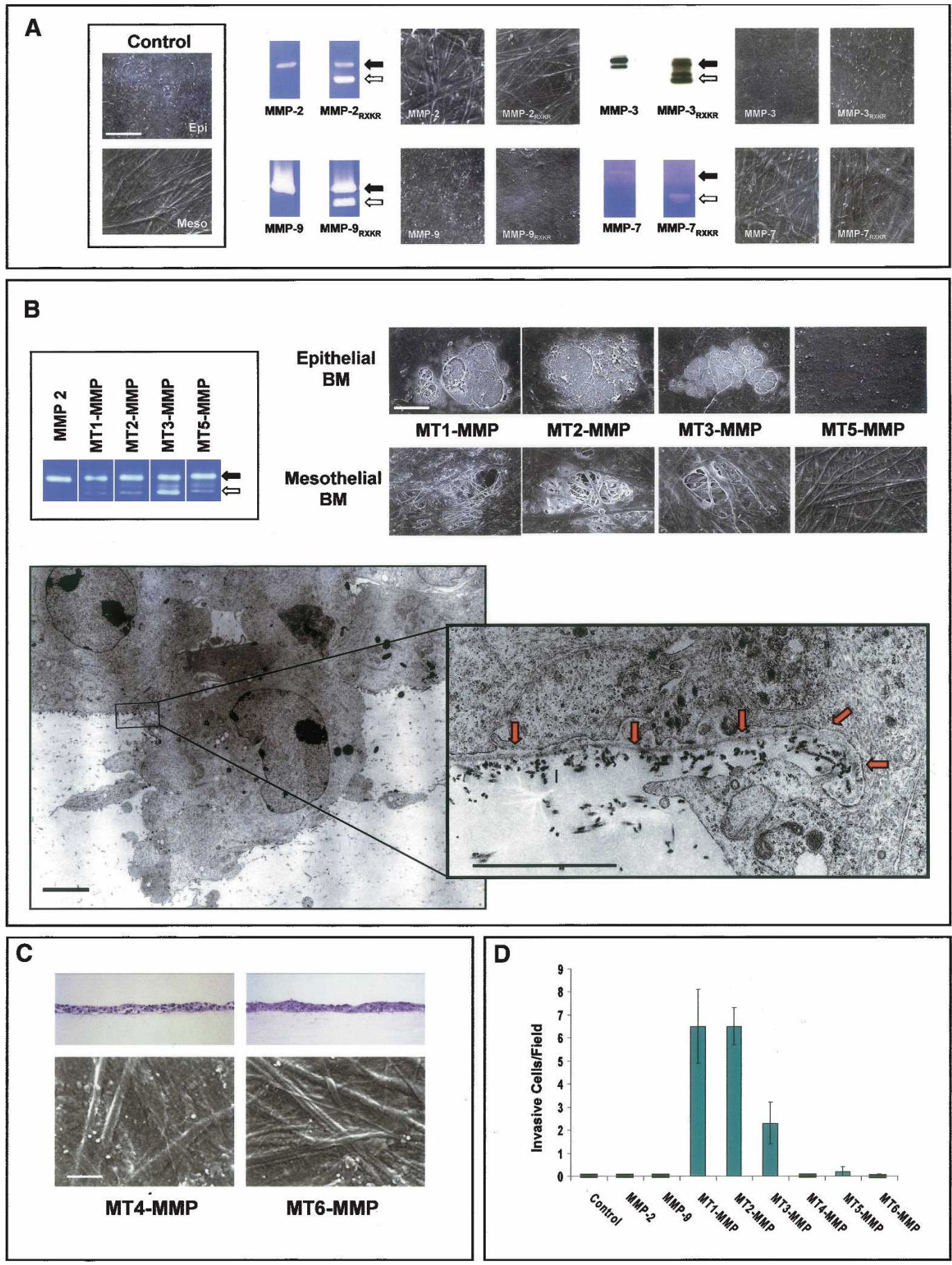

Figure 3. MT-MMP-mediated BM transmigration. (A) Control COS cells or COS cells transiently expressing either wild-type or RXKR (active) forms of MMP-2, MMP-9, MMP-3, or MMP-7 were cultured on mesothelial or epithelial BMs for $5 \mathrm{~d}$, detergent-lysed, and visualized by SEM in representative samples (identical results were obtained with either BM type). Black arrows indicate proMMPs and white arrows indicate processed MMPs as determined by zymography (MMP-2, MMP-7, and MMP-9) or Western blot analysis (MMP-3). (B) Following culture of transfected cells atop BMs, SEM analysis shows discrete fields of perforations in epithelial or mesothelial BMs by MT1-MMP, MT2-MMP, or MT3-MMP, but not MT5-MMP-expressing COS cells. Zymograms show processing of exogenous MMP-2 by COS cells expressing MT1-MMP, MT2-MMP, MT3-MMP, or MT5-MMP (box). TEM shows an MT2-MMPexpressing COS cell inserting an invasive pseudopod through the epithelial BM (red arrows in inset) into the underlying stroma. $(C)$ COS cells expressing MT4-MMP or MT6-MMP were unable to invade or remodel the underlying peritoneal BM as assessed in H\&E-stained cross-sections or by SEM. (D) The number of invasive COS cells was determined in H\&E-stained cross-sections of epithelial BM cultures. Results are shown as the mean number of invasive cells per field \pm standard error of mean $(n=3)$. Bars for TEM and SEM are 1 and $50 \mu \mathrm{m}$, respectively. 
Hotary et al. 2003). Nonetheless, while COS cells transfected with MMP-2/RXKR or MMP-9/RXKR expression vectors secrete high concentrations of the active proteinases as assessed by zymography, the active enzymes are unable to support BM degradation or COS cell transmigration (Fig. 3A). Similarly, though indirect evidence has linked the expression of MMP-3 (stromelysin-1), MMP-7 (matrilysin), as well as MMP-11 (stromelysin-3) to BM remodeling activity (Egeblad and Werb 2002), COS cells expressing neither the latent nor active forms of the respective proteinases degrade or traverse the BM barrier (Fig. 3A). Attempts to establish a potential role for MMP-1 (collagenase-1), MMP-13 (collagenase-3), or MMP-19 in BM remodeling or invasion were likewise unsuccessful (Supplementary Fig. 1). The inability of secreted MMPs to support BM invasion is further supported by the fact that high concentrations of TIMP-1, an endogenous inhibitor that preferentially targets secreted MMPs (Hotary et al. 2003; Overall and Kleifeld 2006), does not inhibit BM remodeling by any of the cancer cell lines studied (Fig. 2A).

Unlike TIMP-1, the metalloproteinase inhibitors, BB94 and TIMP-2, not only inhibit secreted MMPs, but also the subclass of type I transmembrane MMPs (i.e., MT1MMP, MT2-MMP, MT3-MMP, and MT5-MMP) (Hotary et al. 2003). Remarkably, COS cells expressing either MT1-MMP, MT2-MMP, or MT3-MMP acquire the ability to both perforate and transmigrate peritoneal or epithelial BMs (Fig. 3B-D). Scanning electron microscopy (SEM) and transmission electron microscopy (TEM) analyses demonstrate that MT-MMP-expressing COS cells actively remodel the subjacent matrices during the early stages of invasion by inserting pseudopodia directly through the BM into the underlying interstitium (Fig. 3B). Using high-magnification TEM, the sharply cut edges of the perforated BM can be seen to curl away from the body of the invasive membrane protrusions extended by the MT-MMP-transfected COS cells (Fig. 3B, inset). COS cells expressing MT1-MMP, MT2-MMP, or MT3MMP do not display increased motility when cultured atop gelatin-coated Transwell filters or increased twodimensional migratory activity when cultured atop the surface of denuded BMs (data not shown). Though MT5MMP, as well as the glycophosphatidylinositol-anchored MMPs, MT4-MMP and MT6-MMP, have been assigned limited matrix-degrading activity and postulated to play a role in regulating invasive activity (Itoh and Seiki 2006), none of these MT-MMP family members displayed BM remodeling activity (Fig. 3B-D). Hence, only MT1-MMP, MT2-MMP, or MT3-MMP can serve as direct-acting proteases that are capable of dissolving the intervening BM while simultaneously inducing transmigration.

\section{Structural determinants of MT-MMP-dependent BM transmigration}

Following proteolytic processing, the N-terminal propeptide regions of the MT-MMPs are shed, and the active proteases displayed at the cell surface (Yana and Weiss
2000). Proteolytically-active MT1-MMP, MT2-MMP, and MT3-MMP all share a conserved modular structure comprised of a zinc-containing catalytic domain, a hemopexin-like C-terminal domain and a single-pass transmembrane domain that terminates in a short cytosolic tail (Itoh and Seiki 2006). Current evidence suggests that the substrate specificity of each MT-MMP catalytic domain is directed by its hemopexin cassette, while both the distribution of the protease at the cell surface as well as its intracellular trafficking are controlled by motifs embedded in the cytosolic tail (Itoh and Seiki 2006). To identify the structural requirements that underly BM degradation and transmigration, COS cells were transfected with a series of MT-MMP mutants and chimeric constructs wherein each of these proteinase domains were targeted. As shown in Figure 4, MT1-MMP is only able to confer invasive activity when expressed as a catalytically active, membrane-tethered proteinase; i.e., neither BM remodeling nor invasion (data not shown) occurs when MT1-MMP is expressed either as an inactive mutant harboring an $\mathrm{E} \rightarrow \mathrm{A}^{240}$ substitution in its catalytic domain or when MT1-MMP, MT2-MMP, or MT3MMP are expressed as transmembrane-deleted, but catalytically active, soluble enzymes. Despite the reported importance of presenting the MT-MMPs as membranetethered enzymes whose respective cytosolic domains regulate proteinase trafficking (Itoh and Seiki 2006), MT1-MMP retains full BM-degradative activity (as well as invasive activity) (data not shown) when expressed as a membrane-anchored enzyme devoid of its cytosolic tail (Fig. 4A).

Following the delivery of MT1-MMP to the cell surface, the C-terminal hemopexin domain has been proposed to support a homodimerization process that defines proteinase function and activity (Itoh and Seiki 2006). Further, the MT-MMP hemopexin domain not only confers the enzyme with substrate-binding activity, but also exhibits a triple helicase that serves to unwind collagen trimers so as to allow the enzyme's catalytic domain successive access to the individual collagen chains (Tam et al. 2004). Surprisingly, however, an MT1MMP construct devoid of the 12-kD hemopexin domain confers COS cells with full ability to degrade intact BMs (Fig. 4B).

Given the unexpected ability of hemopexin-deleted MT1-MMP to drive BM invasion, we considered the possibility that other membrane-tethered, catalytically active MMPs might confer recipient COS cells with similar BM remodeling activities. Hence, gelatinase $\mathrm{A}$ or gelatinase B chimeras were engineered to allow the active proteinases to be tethered to the cell surface by the MT1-MMP transmembrane and cytosolic domains. However, despite the display of the proteolytically active chimeras at the COS cell surface, neither construct was able to confer BM-degradative or invasive activities (Fig. 4B). These results rule out the possibility that membrane-tethered MMPs per se harbor structural information sufficient for BM transmigration, and further support the contention that neither MMP-2 nor MMP-9 can directly mediate BM turnover in a fashion that supports 

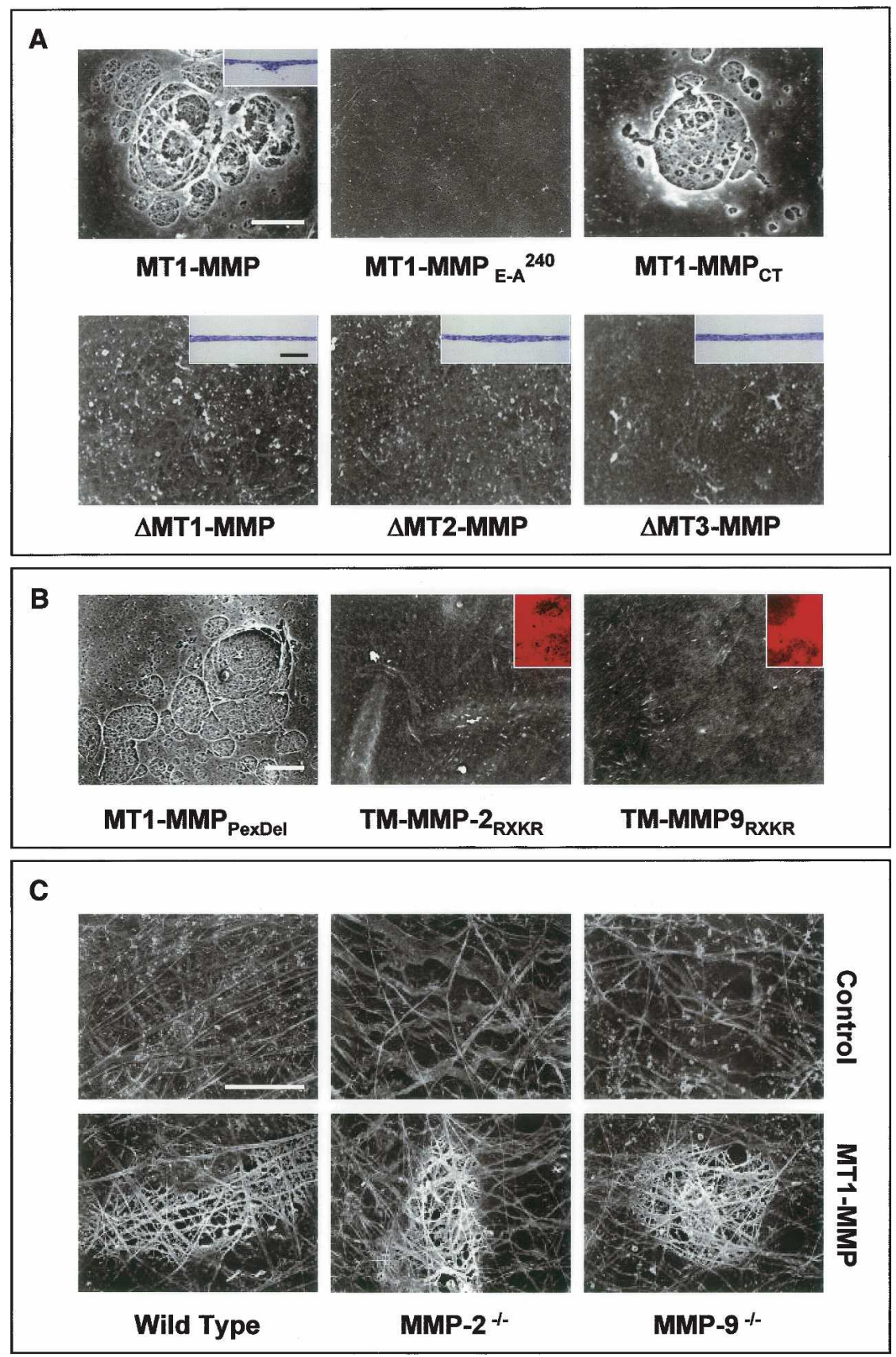

Figure 4. Structure-function analysis of MT-MMP-mediated BM proteolysis. (A) COS cells were transfected with MT1MMP; catalytically inactive MT1-MMP $\left(\mathrm{MT} 1-\mathrm{MMP}_{\mathrm{E} \rightarrow \mathrm{A}}{ }^{240}\right)$; cytoplasmic tail-deleted MT1-MMP (MT1-MMP $\left.{ }_{\mathrm{CT}}\right) ; \quad$ or soluble, transmembrane-deleted forms of MT1-MMP, MT2-MMP, or MT3-MMP

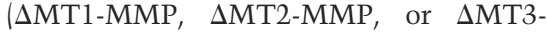
MMP) and cultured atop epithelial BMs for a 5-d culture period. Cells were removed and the underlying BM was assessed by $\mathrm{SEM}$. Insets show representative $\mathrm{H} \& \mathrm{E}$ stained cross-sections. $(B)$ COS cells were transfected with an MT1-MMP construct wherein the hemopexin domain was deleted (MT1-MMP $\left.{ }_{\text {PexDel }}\right)$ or, alternatively, with chimeric forms of either membraneanchored, active MMP-2 or MMP-9 (TMMMP- $2_{\text {RXKR }}$ or TM-MMP- $9_{\mathrm{RXKR}}$, respectively). Following a 5-d culture period, BM structure was assessed by SEM. Insets demonstrate the ability of the membraneanchored gelatinases to degrade a subjacent bed of fluorescent gelatin. (C) Mesothelial BMs isolated from wild-type, MMP-2-/-, or MMP-9-/- mice were visualized by SEM after a 5-d culture period in the respective null serum with control or MT1-MMP-transfected COS cells. Bars for SEM and light micrographs are 10 and 100 $\mu \mathrm{m}$, respectively. the invasion program. MT-MMPs are, however, able to process MMP-2 to its active form, which in turn can initiate an MMP-9 activation cascade (Itoh and Seiki 2006). As such, MT1-MMP could conceivably remodel the BM only in collaboration with MMP-2 or MMP-9. As MMP-2 and MMP-9 not only circulate in plasma, but may also be embedded in the BM or its surrounding tissues, MT1-MMP-expressing COS cells were cultured atop BMs isolated from either $M M P-2^{-/-}$or $M M P-9^{-/-}$ mice and suspended in the presence of the respective null sera. Despite the complete absence of MMP-2 or MMP-9 under these conditions, neither BM remodeling (Fig. 4C) nor invasion (data not shown) are affected.
MT-MMPs are both necessary and sufficient for BM invasion by human cancer cells

Among the carcinoma cell lines studied, the phenotypic behavior of the breast cancer cell lines MDA-MB-231 and MCF-7 are diametrically opposed in vitro and in vivo (Fujita et al. 2003; Hotary et al. 2003). Akin to aggressive breast carcinoma lesions in vivo (Ueno et al. 1997), MDA-MB-231 cells are highly invasive and express predominately MT1-MMP and MT2-MMP (MT3-MMP is only intermittently detected) (Fig. 5; data not shown). In contrast, MCF-7 display a more indolent behavior in vivo, and express little, if any, of the BM invasive MT- 
Hotary et al.
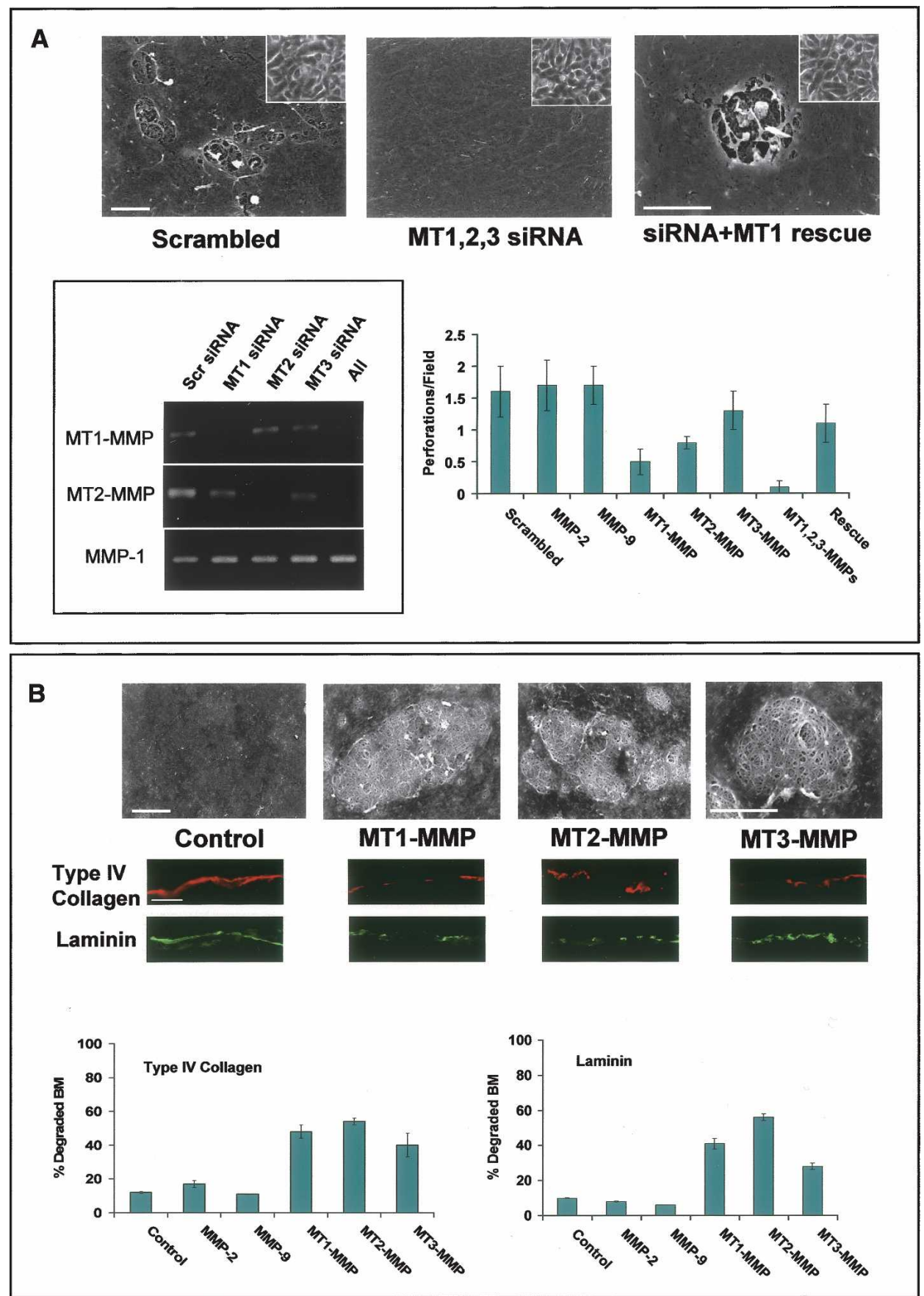

Figure 5. MT-MMP-dependent control of carcinoma cell BM invasion. (A) MDA-MB-231 cells were electroporated with either a scrambled siRNA or MT1-MMP, MT2-MMP, and MT3-MMP siRNA in combination, and then cotransfected with a control or mouse MT1-MMP expression vector (rescue). After a 5-d culture period atop epithelial BMs, matrices were denuded and examined by SEM. Insets show tumor cell morphology following electroporation as assessed by phase contrast microscopy. MT1-MMP, MT2-MMP, and MT3-MMP siRNAs inhibited expression of the targeted proteases, but had no effect on the expression of nontargeted MMPs as shown by RT-PCR (box). The chart shows the average number of BM perforations quantified in 25 randomly selected fields for each siRNA transfection and rescue (mean \pm standard error of mean; $n=3$ ). (B) Epithelial BM structure, as assessed by SEM (with corresponding type IV collagen and laminin immunofluorescence below), following a 5-d culture period with control-, MT1-MMP-, MT2-MMP-, or MT3-MMP-transfected MCF-7 cells. Bar charts depict the percent degraded BM (i.e., loss of visible type IV collagen or laminin fluorescence) quantified in 10 random fields. All bars are shown \pm standard error of the mean. Bars for SEM and light micrographs are 10 and $100 \mu \mathrm{m}$, respectively. 
MMPs (Hotary et al. 2003). Hence, we sought to characterize (1) the impact of silencing $M T 1-M M P, M T 2-M M P$, and $M T 3-M M P$ on the BM remodeling potential of MDAMB-231 cells and, conversely, (2) the ability of either $M T 1-M M P, M T 2-M M P$, or MT3-MMP to endow invasion-null MCF-7 cells with a BM-invasive phenotype.

Following electroporation with a scrambled small interfering RNA (siRNA) construct, MDA-MB-231 cells retain the ability to perforate and transmigrate the intact BM (Fig. 5A). Further, as predicted, siRNAs directed against either $M M P-2$ or $M M P-9$ are unable to interfere with BM remodeling (Fig. 5A). In contrast, while the specific siRNA-mediated silencing of either $M T 1-M M P$, MT2-MMP, or MT3-MMP did not affect MDA-MB-231 cell morphology or adhesion, BM perforation and invasion are inhibited by as much as $70 \%$ (Fig. 5A; data not shown). These findings are not restricted to BMs recovered from animal species, as MT-MMPs similarly confer cancer cells with the ability to perforate and traverse BMs isolated from human tissue (Supplementary Fig. 2). Moreover, when all three $M T-M M P$ s are silenced, MDAMB-231 cells (as well as HT-1080 cells) (data not shown) are completely unable to either remodel or transmigrate the underlying BM (Fig. 5A). Following re-expression of a mouse MT1-MMP ortholog that escapes siRNA targeting directed against the human proteinases, BM remodeling and transmigration activities are reconstituted in MDAMB-231 cells that no longer express their endogenous complement of human MT1-MMP, MT2-MMP, or MT3MMP (Fig. 5A).

In contradistinction to MDA-MB-231 cancer cells, the invasive activity of MCF-7 cells is normally held in check by estrogen receptor-regulated transcriptional corepressors (Fujita et al. 2003). To finally determine whether regulatory checkpoints might be bypassed by downstream-acting MMPs, MCF-7 cells were transfected transiently with either MT1-MMP, MT2-MMP, or MT3$M M P$ expression vectors and BM remodeling activity monitored. As expected, control MCF-7 cells are completely unable to traverse $(0 \pm 0$ invasive cells/field; mean \pm standard error of mean, $n=6$ ) or remodel the underlying BM as assessed by SEM (Fig. 5B). Importantly, MT1-MMP, MT2-MMP, or MT3-MMP were each able to confer MCF-7 cells with the ability to perforate and transmigrate the BM (Fig. 5B; Supplementary Fig. 3). Hence, MT1-MMP, MT2-MMP, and MT3-MMP are not only necessary, but sufficient for driving cancer cell-mediated BM remodeling and invasion.

\section{Discussion}

As tumor cells undergo the transition from a benign to cancerous state, gene programs are accessed that arm neoplastic cells with the ability to perforate abutting BMs (Hanahan and Weinberg 2000). While BMs comprise only a small part of the overall ECM mass, the covalently cross-linked, interlocking network of type IV collagen and associated macromolecules serves as the major structural barrier to advancing tumor cells (Kalluri
2003). Indeed, within the primary neoplastic nest, cancer cells confined by an as-yet-intact BM-i.e., the so-called carcinoma in situ-harbor a favorable clinical prognosis. In contrast, cancer cells that acquire invasive activity and perforate the intervening BM portend a more dire outcome (Hanahan and Weinberg 2000). Despite the fact that BM transmigration serves as a rate-limiting step in the mobilization of the malignant phenotype, the molecular machinery underlying this specialized form of ECM remodeling has remained undefined (Sherwood 2006). Herein, we identify a triad of membrane-anchored metalloproteases that are embedded with all of the structural information necessary to directly confer human cancer cells with the ability to proteolyze, perforate, and transmigrate BM barriers.

\section{BM remodeling: a $M M P$-dependent process}

To date, multiple classes of proteolytic enzymes have been proposed to act as key participants in BM transmigration (e.g., Mignatti et al. 1986; Kalluri 2003). However, studies implicating serine, cysteine, or aspartyl proteinases have relied almost entirely on (1) the use of artificial BM constructs that do not recapitulate accurately the structural characteristics of the in vivo or ex vivoassembled matrix or (2) in vivo systems that fail to directly track the dynamic interactions that occur between advancing cancer cells and the surrounding BM (EvanRam and Yamada 2005). While acellular BM sheets have been used periodically in earlier studies (e.g., Mignatti et al. 1986), these constructs frequently contain pores that can permit transmigration to proceed independently of proteolysis (Aplin et al. 1985; Howat et al. 2001). In our system, we developed an ex vivo model of invasion, wherein cancer cell lines are held in juxtaposition with intact BMs in long-term culture, and changes in BM architecture evaluated directly. Under these conditions, neoplastic cells proteolytically remodel the subjacent networks of BM macromolecules, assemble and insert pseudopodia through the associated perforations, and transmigrate the BM defects in a fashion that recapitulates each of the major steps involved in cancer cell invasion in vivo (Sherwood 2006). Further, we find that cancer cell-mediated BM remodeling and invasion proceed via a MMP-dependent process. At a glance, these observations appear to contradict at least three major bodies of literature. First, in clinical trials, MMP inhibitors have failed to exert the predicted beneficial effects (Coussens et al. 2002; Overall and Kleifeld 2006). These results have lent strength to the contention that the multiplicity of proteinases operative in cancer cells preclude their reliance on any single proteolytic system (Coussens et al. 2002; Egeblad and Werb 2002; Overall and Kleifeld 2006). Interestingly, however, our data suggest a more trivial explanation for the apparent failure of MMP inhibitor-based interventions-i.e., the peak plasma concentrations of synthetic inhibitors reached in the clinical setting (e.g., Denis and Verweij 1997) fall far below those needed to quench critical proteolytic events that occur within the sequestered microenvironments 
that exist at the tightly apposed, tumor cell-BM interface. Second, other studies have documented roles for other proteolytic systems in tumorigenesis, particularly in the in vivo setting (e.g., Gocheva et al. 2005; LaurentMatha et al. 2005). However, caution need be exercised in assigning a given proteinase's role to the direct regulation of invasive activity. Indeed, an increasing body of work has demonstrated that proteinases indirectly affect cell behavior by generating chemokines, motility, and growth factors or regulating cell-cell and cell-matrix adhesive interactions (Egeblad and Werb 2002; Radisky et al. 2005; Itoh and Seiki 2006). In our ex vivo studies, potent inhibitors previously demonstrated to effectively target serine, cysteine, or aspartyl proteinases in intact cell systems (e.g., Rosenthal et al. 1998; Filippov et al. 2003,2005 ) fail to affect cancer cell-BM interactions or transmigration. Third, recent reports have stressed the ability of tumor cells to adopt an amoeboid phenotype in order to negotiate ECM barriers by protease-independent schemes (Friedl and Wolf 2003). However, such conclusions were reached using reconstituted BM extracts (i.e., Matrigel) as the barrier construct. In contrast to authentic BMs, wherein structural integrity is assigned to a type IV collagen polymer that is cross-linked by intermolecular disulfide, aldimine, and hydroxylysine-methionine bonds, the macromolecular network found in Matrigel is dominated by noncovalent forces alone (Evan-Ram and Yamada 2005; Than et al. 2005; Vanacore et al. 2005). Apparently, proteinase-independent schemes can only be mobilized under conditions in which BM cross-links have been disrupted. Though it is conceivable that type IV collagen cross-links may be dissociated reversibly during invasive events (e.g., intermolecular disulfide bonds arrangements can be reshuffled by protein disulfide isomerases), none of the eight cancer cells we examined traverse intact BMs without mobilizing MMP activity.

\section{An MT-MMP triad directs BM proteolysis}

In human cancers, a diverse array of human MMP family members have been found to be expressed within the mass of advancing tumor tissue (Overall and Kleifeld 2006). Yet, the role that specific MMPs play in BM remodeling has remained unresolved. Presumably, to invest a given cell population with a BM-remodeling activity, a proteolytic activity must be envisioned that can efface the $>50$ matrix molecules that are noncovalently associated with a scaffolding of cross-linked type IV collagen. In turn, the type IV polymer must be cleaved in a productive fashion that allows adhesive ligands to either be retained, or newly generated, which then serve to support the forward propulsive movement of the invading cell. Consistent with these multiple requirements for transmigration, MMP family members display omnivorous, ECM-degrading activities (Egeblad and Werb 2002; Overall and Kleifeld 2006). Further, the type IV collagen triple helix itself is interrupted by no fewer than 22 protease-sensitive, nonhelical domains (Kalluri 2003). As such, the previously reported abilities of secreted
MMPs to hydrolyze soluble type IV collagen under cellfree conditions would seem to support the contention that these enzymes could play a direct role in BM invasion. However, in contrast to the isolated type IV collagen molecules that are standardly analyzed as solutionphase substrate targets, the cross-linked network of type IV collagen heterotrimers encountered in situ assumes a far more stable and protease-resistant conformation (Linsenmayer et al. 1984; Eble et al. 1996). Indeed, COS cells engineered to express high concentrations of various members of the secreted MMP family that have been linked indirectly to $\mathrm{BM}$ remodeling events such as, MMP-2, MMP-3, MMP-9, MMP-11, or MMP-13 did not acquire BM-invasive activity (Hanahan and Weinberg 2000; Kalluri 2003; Overall and Kleifeld 2006). Given the broad substrate repertoire of these MMPs, it seems unlikely that no BM-associated components were cleaved (e.g., Mott et al. 1997). Nevertheless, these MMPs were unable to remodel the BM to a degree where focal defects materialized or invasive activity was promoted. While controversial, these findings are entirely consistent with an increasing body of work demonstrating that mice harboring inactivating mutations in secreted MMPs exhibit largely unaffected invasive phenotypes (e.g., Baluk et al. 2004; McCawley et al. 2004; Hartenstein et al. 2006). Nevertheless, in contrast to the inability of the secreted MMPs to support BM remodeling, three members of the membrane-anchored subfamily of MMPs have been identified that can invest host cells with the ability to traverse BMs in a manner that phenocopies the behavior of invasive cancer cell populations. Despite the distinct structure of each of their respective catalytic domains (Itoh and Seiki 2006; Overall and Kleifeld 2006), MT1MMP, MT2-MMP, and MT3-MMP each display indistinguishable BM remodeling and proinvasive behaviors. Like other MMP family members, MT-MMPs can degrade a variety of BM-associated macromolecules (Itoh and Seiki 2006). Though MT1-MMP, MT2-MMP, or MT3-MMP have not been reported previously to degrade isolated type IV collagen, the ability of each of these proteinases to completely efface the BM wall indicates that protease-sensitive sites are exposed in the type IV collagen network in situ. Importantly, these activities are not generally shared by other MT-MMP family members (i.e., MT4-MMP, MT5-MMP, or 6-MMP) or their artificially engineered counterparts; e.g., membrane-anchored forms of MMP-2 or MMP-9. Apparently, the catalytic domains of MT1-MMP, MT2-MMP, and MT3MMP have been designed specifically to accommodate each of the major structural components required for BM remodeling. Interestingly, studies of BM removal during anchor cell invasion in C. elegans have implicated an MT-MMP-like, GPI-anchored enzyme that potentially subserves functions similar to those we describe for cancer cell MT-MMPs (Sherwood et al. 2005). Though silencing this specific metalloprotease exerted little effect on anchor cell BM invasion, C. elegans express at least three $M T-M M P$ orthologs and may, like humans, use a complement of these enzymes to drive the invasion program (Wada et al. 1998). 


\section{MT-MMPs as molecular motors}

By fusing proteolytic activity to the cell surface, MT1MMP, MT2-MMP, and MT3-MMP are ideally situated to ensure that high concentrations of the active protease are apposed directly to the underlying substrate. Indeed, $\mathrm{BM}$ remodeling is no longer detected when MT-MMPs are expressed in a transmembrane-deleted, secreted form rather than in their wild-type, membrane-tethered format. Presumably, the loss of subjacent proteolytic activity reflects the expected decrease in the effective enzyme:substrate ratio at the cell-BM interface. Moreover, in the absence of membrane tethering, active MT-MMPs would diffuse away from the cell surface and fall prey to inhibition by serum-borne antiproteinases (Weiss 1989).

While membrane tethering is critical to BM-remodeling activity, our findings stand in contrast to recent studies that have suggested that the MT-MMP cytoplasmic domain plays a necessary role in both directing the protease to the cell-substratum interface and transducing intracellular signaling cascades (for review, see Itoh and Seiki 2006). As demonstrated, the tail-deleted MT-MMP mutants retain full degradative activity during BM remodeling, trigger the assembly of invasive pseudopodlike structures at the cell surface, and propagate transmigration as well. Likewise, while MT1-MMP has been reported to induce rac-dependent motility independent of its proteolytic activity (Cao et al. 2004), we find that catalytically inactive MT1-MMP is unable to support cell trafficking across BMs. Interestingly, a dual requirement for membrane-anchoring and proteolytic activity is consistent with reports that MMPs can "walk" over a matrix-coated substratum via a biased diffusion process, whereby the protease binds and then cleaves substrate molecules (Saffarian et al. 2004). As enzyme-type IV collagen-binding interactions are likely weakened following proteolysis and the consequent thermal denaturation of the type IV collagen trimers, backward diffusion across the denatured substratum is prohibited. In this scenario, the membrane-anchored protease may "pull" or guide the cell forward by forming successive adhesive interactions with uncleaved substrate. We anticipated that this active diffusion process might require an intact MTMMP hemopexin domain, as both triple helicase and collagen-binding activities have been associated with this C-terminal portion of the protease (Cao et al. 2004; Tam et al. 2004). However, BM proteolytic, and invasive activities are retained in the hemopexin-deleted enzyme. Nonetheless, as the MT1-MMP catalytic domain may display both hydrolytic and helicase activities (Pelman et al. 2005), our results support a model wherein the truncated, but catalytically active protease, contains sufficient structural information to effectively drive the BM remodeling and transmigration programs.

\section{MT-MMPs in cancer}

In normal tissues, the BM plays a key role in regulating cell adhesion, migration, differentiation, and growth (Kalluri 2003). Cancer cell-dependent proteolysis of BM components not only serves to disrupt these regulatory interactions, but also allows for the generation of a wide range of bioactive ECM fragments that can participate in tumorigenesis by affecting events ranging from tumor cell motility to angiogenesis (Egeblad and Werb 2002; Kalluri 2003). Further, as migrating cancer cells cross the degraded BM and gain access to interstitial matrix components, new ECM-receptor interactions are established that activate gene programs that accelerate the loss of differentiated phenotype (Brabletz et al. 2004). As MT1$M M P, M T 2-M M P$, and $M T 3-M M P$ are widely expressed in a wide range of human cancer cells-both at primary and micrometastatic sites (Klein et al. 2002; Itoh and Seiki 2006)—we propose that this MMP triad is purposefully mobilized to initiate BM remodeling and drive the invasive phenotype in vivo. While we have used MCF-7 and MDA-MB-231 breast-cancer cells as "prototypical" carcinomas, it is important to note that each of the seven cancer cell lines used in our study rely on TIMP-2-sensitive MT-MMPs to negotiate authentic BM barriers. Though increased attention has focused on the ability of stroma or leukocyte-derived proteases to participate in tumor progression (Egeblad and Werb 2002), our findings demonstrate that the expression of either MT1-MMP, MT2-MMP, or MT3-MMP is sufficient to confer tumor cells with the ability to dismantle and transmigrate BMs independently of any accessory cell population.

Having crossed the BM barrier, cancer cells find themselves embedded in a structurally distinct, three-dimensional ECM composite (Hanahan and Weinberg 2000; Evan-Ram and Yamada 2005). As MT-MMPs can support a series of matrix remodeling events necessary to accommodate three-dimensional cell proliferation, tissue-invasive activity, and differentiation programs as well (Hiraoka et al. 1998; Hotary et al. 2000, 2002, 2003; Sabeh et al. 2004; Chun et al. 2006), our findings suggest that this specialized triad may serve as multipurpose regulators of the cancer cell phenotype.

\section{Materials and methods}

\section{Cell lines}

Cells were obtained from ATCC with the exception of the squamous cell carcinoma line, SCC-1 (T. Carey, University of Michigan). All Cells were maintained in DMEM supplemented with $10 \%$ FBS, L-glutamine $(2 \mathrm{mM})$ and penicillin $(100 \mathrm{U} / \mathrm{mL}) /$ streptomycin $(100 \mu \mathrm{g} / \mathrm{mL})$. MCF-7 cell medium was further supplemented with $10 \mu \mathrm{g} / \mathrm{mL}$ insulin (Hotary et al. 2003).

\section{$B M s$}

Peritoneal BM (Witz et al. 2001) was prepared by stripping the overlying mesothelial cells from rat or mouse (wild type, $\mathrm{MMP2}^{-/-}$, or $\mathrm{MMPO}^{-/-}$) mesentery using $1 \mathrm{~N}$ ammonium hydroxide and mounting the isolated mesentery on $6.5-\mathrm{mm}$ diameter Transwells. Alternatively, BMs were assembled by a clonal MDCK epithelial cell line cultured atop type I collagen gels in the upper wells of Transwell dishes (Ecay and Valentich 1992; Erickson and Couchman 2001). After a 3-wk culture period, the cells were stripped with deoxycholate in hypotonic buffer (10 $\mathrm{mM}$ Tris $\mathrm{HCl}, 0.1 \% \mathrm{BSA}, 0.1 \mathrm{mM} \mathrm{CaCl}_{2}$ at $\mathrm{pH} 7.5$ ) followed by 
$0.5 \%$ NP-40 in hypotonic buffer. All experiments were run in complete medium (above), unless otherwise indicated, in the absence or presence of protease inhibitors $(5 \mu \mathrm{M}$ BB-94, 12.5 $\mu \mathrm{g} / \mathrm{mL}$ TIMP-1, $5 \mu \mathrm{g} / \mathrm{mL}$ TIMP-2, $200 \mu \mathrm{g} / \mathrm{mL}$ aprotinin, 100 $\mu \mathrm{g} / \mathrm{mL}$ soybean trypsin inhibitor, $100 \mu \mathrm{M}$ E-64, or $50 \mu \mathrm{M}$ pepstatin), which were added with each medium change at $48-72 \mathrm{~h}$ (Hotary et al. 2003). Mesothelial and epithelial BMs were used interchangeably with similar, if not identical, results obtained on either matrix. In selected experiments, tumor cell invasion was also assessed using Matrigel barriers $(13 \mathrm{mg} / \mathrm{mL}$; BD Biosciences) applied as either a thin $(50-\mu \mathrm{L})$ or thick $(500-\mu \mathrm{L})$ coat atop Transwell filters.

\section{Expression vector construction and transfection}

COS-1 and MCF-7 cells were transiently transfected with control vector (PCR3.1-Uni) or expression vectors encoding human MT1-MMP through MT6-MMP, transmembrane-deleted forms

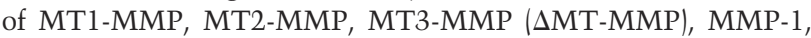
MMP-2, MMP-3, MMP-7, MMP-9, MMP-11, MMP-19 (wildtype or proprotein convertase-activatable $\left[\mathrm{MMP}_{\mathrm{RXKR}}\right]$ forms), a membrane-anchored, proprotein convertase-activatable form of MMP-2 (gift of S. Zucker and J. Cao, State University of New York at Stony Brook), or MMP-9 (TM-MMP $\mathrm{RXKR}_{\mathrm{R}}$ ), using Fugene6 (Koshikawa et al. 2000; Hotary et al. 2003). Cytoplasmic tail-deleted MT1-MMP and hemopexin-deleted MT1-MMP were prepared as described (Hotary et al. 2003; Wang et al. 2004). Expression levels were confirmed by Western blot and/or zymography as described previously (Hotary et al. 2003). MTMMP activity was monitored as a function of the ability of transfected cells to process exogenous MMP-2 as assessed by zymography (Hotary et al. 2003).

\section{SiRNA electroporation}

siRNAs were targeted against 21-nucleotide sequences of MT1MMP $\quad$ (5'-AACAGGCAAAGCTGATGCAGA- ${ }^{\prime}$; nucleotides 228-248), MT2-MMP (5'-AAGGCCAAGTGGTCCGTGTGA3'; nucleotides 650-670), MT3-MMP (5'-AAGCCAATCACAGTCTGGAAA-3'; nucleotides 1423-1443), MMP-2 (5'AATACCATCGAGACCATGCGG-3'; nucleotides 274-294), or MMP-9 (5'-AAGGAGTACTCGACCTGTACC-3'; nucleotides 1066-1086). A control siRNA sequence was generated from a scrambled MT1-MMP sequence (5'-AAGTGATCAAGCACCGAAGAG-3'). Tumor cells were electroporated with siRNA oligonucleotides (50-100 nM) using a nucleofector kit (Amaxa) with $>90 \%$ transfection efficiency (Sabeh et al. 2004). Targeted protein expression was knocked down by $95 \%$ or more for up to $72 \mathrm{~h}$ (Sabeh et al. 2004). For rescue experiments, tumor cells were cotransfected with mouse MT1-MMP (gift of M. Seiki, University of Tokyo). MMP expression and siRNA knockdown were confirmed by RT-PCR as described previously (Sabeh et al. 2004).

\section{Light, fluorescence, and electron microscopy}

For light microscopy, BM cultures were fixed in $4 \%$ paraformaldehyde in PBS, paraffin-embedded, sectioned, and stained with hematoxylin and eosin (H\&E) (Hotary et al. 2003; Sabeh et al. 2004). The number of invading cells per microscopic field was determined as described (Hotary et al. 2000; Sabeh et al. 2004). Immunofluorescence was performed on frozen sections fixed in $1 \%$ paraformaldehyde and incubated with monoclonal (type IV collagen; Oncogene Research Products) or polyclonal (Laminin; Sigma) antibodies and visualized with the appropriate Texas red- or fluorescein-labeled secondary antibodies. De- graded type IV collagen was detected using monoclonal antibody HUIV26 (Xu et al. 2001).

BM structure was visualized by SEM after cells were stripped from the BMs by either detergent or ammonium hydroxide lysis. For both SEM and TEM, cultures were fixed in $2 \%$ glutaraldehyde/1.5\% paraformaldehyde in $0.1 \mathrm{M}$ cacodylate buffer, post-fixed in $1 \%$ osmium tetroxide, and dehydrated through a graded ethanol series as described (Hotary et al. 2003).

\section{Acknowledgments}

This work was supported by NIH grants R01 CA88308 and R01 CA71699.

\section{References}

Abrams, G.A., Goodman, S.L., Nealey, P.F., Franco, M., and Murphy, C.J. 2000. Nanoscale topography of the basement membrane underlying the corneal epithelium of the rhesus macaque. Cell Tissue Res. 299: 39-46.

Aplin, J.D., Campbell, S., and Allen, T.D. 1985. The extracellular matrix of human amniotic epithelium: Ultrastructure, composition and deposition. J. Cell Sci. 79: 119-136.

Baluk, P., Raymond, W.W., Ator, E., Coussens, L.M., McDonald, D.M., and Caughey, G.H. 2004. Matrix metalloproteinase-2 and -9 expression increases in mycoplasma-infected airways but is not required for microvascular remodeling. Am. J. Physiol. Lung Cell. Mol. Physiol. 287: L307-L317.

Brabletz, T., Spaderna, S., Kolb, J., Hlubek, F., Faller, G., Bruns, C.J., Jung, A., Nentwich, J., Duluc, I., Domon-Dell, C., et al. 2004. Down-regulation of the homeodomain factor Cdx2 in colorectal cancer by collagen type I: An active role for the tumor environment in malignant tumor progression. Cancer Res. 64: 6973-6977.

Cao, J., Kozarekar, P., Pavlaki, M., Chiarelli, C., Bahou, W.F., and Zucker, S. 2004. Distinct roles for the catalytic and hemopexin domains of membrane type 1-matrix metalloproteinase in substrate degradation and cell migration. J. Biol. Chem. 279: 14129-14139.

Chun, T.H., Hotary, K.B., Sabeh, F., Saltiel, A.R., Birkedal-Hansen, H., Allen, E.D., and Weiss, S.J. 2006. A pericellular collagenase directs the 3-dimensional development of white adipose tissue. Cell 125: 577-591.

Coussens, L.M., Fingleton, B., and Matrisian, L.M. 2002. Matrix metalloproteinase inhibitors and cancer: Trials and tribulations. Science 295: 2387-2392.

Denis, L.J. and Verweij, J. 1997. Matrix metalloproteinase inhibitors: Present achievements and future prospects. Invest. New Drugs 15: 175-185.

Eble, J.A., Ries, A., Lichy, A., Mann, K., Stanton, H., Gavrilovic, J., Murphy, G., and Kuhn, K. 1996. The recognition sites of the integrins $\alpha_{1} \beta_{1}$ and $\alpha_{2} \beta_{1}$ within collagen IV are protected against gelatinase A attack in the native protein. I. Biol. Chem. 271: 30964-30970.

Ecay, T.W. and Valentich, J.D. 1992. Basal lamina formation by epithelial cell lines correlates with laminin A chain synthesis and secretion. Exp. Cell Res. 203: 32-38.

Egeblad, M. and Werb, Z. 2002. New functions for the matrix metalloproteinases in cancer progression. Nat. Rev. Cancer 2: 161-174.

Erickson, A.C. and Couchman, J.R. 2001. Basement membrane and interstitial proteoglycans produced by MDCK cells correspond to those expressed in the kidney cortex. Matrix Biol. 19: $769-778$. 
Evan-Ram, S. and Yamada, K.M. 2005. Cell migration in 3D matrix. Curr. Opin. Cell Biol. 17: 524-532.

Filippov, S., Caras, I., Murray, R., Matrisian, L.M., Chapman Jr., H.A., Shaprio, S., and Weiss, S.J. 2003. Matrilysin-dependent elastolysis by human macrophages. J. Exp. Med. 198: 925935.

Filippov, S., Koenig, G.C., Chun, T.H., Hotary, K.B., Ota, I., Bugge, T.H., Roberts, J.D., Fay, W.P., Birkedal-Hansen, H., Holmbeck, K., et al. 2005. MT1-matrix metalloproteinase directs arterial wall invasion and neointima formation by vascular smooth muscle cells. J. Exp. Med. 202: 663-671.

Friedl, P. and Wolf, K. 2003. Tumour-cell invasion and migration: Diversity and escape mechanisms. Nat. Rev. Cancer 3: 362-374.

Fujita, N., Jaye, D.L., Kajita, M., Geigerman, C., Moreno, C.S., and Wade, P.A. 2003. MTA3, a Mi-2/NuRD complex subunit, regulates an invasive growth pathway in breast cancer. Cell 113: 207-219.

Gocheva, V., Zeng, W., Ke, D., Klimstra, D., Reinheckel, T., Peters, C., Hanahan, D., and Joyce, J.A. 2006. Distinct roles for cysteine cathepsin genes in multistage tumorigenesis. Genes \& Dev. 20: 543-556.

Hanahan, D. and Weinberg, R.A. 2000. The hallmarks of cancer. Cell 100: 57-70.

Hartenstein, B., Dittrich, B.T., Stickens, D., Heyer, B., Vu, T.H., Teurich, S., Schorpp-Kistner, M., Werb, Z., and Angel, P. 2006. Epidermal development and wound healing in matrix metalloproteinase 13-deficient mice. J. Invest. Dermatol. 126: 486-496.

Hiraoka, N., Allen, E., Apel, I.J., Gyetko, M.R., and Weiss, S.J. 1998. Matrix metalloproteinases regulate neovascularization by acting as pericellular fibrinolysins. Cell 95: 365-377.

Hotary, K., Allen, E., Punturieri, A., Yana, I., and Weiss, S.J. 2000. Regulation of cell invasion and morphogenesis in a three-dimensional type I collagen matrix by membrane-type matrix metalloproteinases 1, 2, and 3. J. Cell. Biol. 149: $1309-1323$.

Hotary, K.B., Yana, I., Sabeh, F., Li, X.Y., Holmbeck, K., Birkedal-Hansen, H., Allen, E.D., Hiraoka, N., and Weiss, S.J. 2002. Matrix metalloproteinases regulate fibrin-invasive activity via MT1-MMP-dependent and independent processes. J. Exp. Med. 195: 295-308.

Hotary, K.B., Allen, E.D., Brooks, P.C., Datta, N.S., Long, M.S., and Weiss, S.J. 2003. Membrane type-1 matrix metalloproteinase usurps tumor growth control imposed by the threedimensional extracellular matrix. Cell 114: 33-45.

Howat, W.J., Holmes, J.A., Holgate, S.T., and Lackie, P.M. 2001. Basement membrane pores in human bronchial epithelium. Am. I. Pathol. 158: 673-680.

Itoh, Y. and Seiki, M. 2006. MT1-MMP: A potent modifier of pericellular microenvironment. J. Cell. Physiol. 206: 1-8.

Kalluri, R. 2003. Basement membranes: Structure, assembly and role in tumour angiogenesis. Nat. Rev. Cancer 3: 422433.

Klein, C.A., Seidl, S., Petat-Dutter, K., Offner, S., Geigl, J.B., Schmidt-Kittler, O., Wendler, N., Passlick, B., Huber, R.M., Schlimok, G., et al. 2002. Combined transcriptome and genome analysis of single micrometastatic cells. Nat. Biotechnol. 20: 387-392.

Koshikawa, N., Giannelli, G., Cirulli, V., Miyazaki, K., and Quaranta, V. 2000. Role of cell surface metalloprotease MT1-MMP in epithelial cell migration over laminin-5. J. Cell Biol. 148: 615-624.

Laurent-Matha, V., Maruani-Herrmann, S., Prebois, C., Beaujouin, M., Glondu, M., Noel, A., Alvarez-Gonzalez, M.L., Blacher, S., Coopman, P., Baghdiguian, S., et al. 2005. Cata- lytically inactive human cathepsin D triggers fibroblast invasive growth. J. Cell Biol. 168: 489-499.

Linsenmayer, T.F., Gibney, E., Fitch, J.M., Gross, J., and Mayne, R. 1984. Thermal stability of the helical structure of type IV collagen within basement membranes in situ: Determination with a conformation-dependent monoclonal antibody. $J$. Cell Biol. 99: 1405-1409.

McCawley, L.J., Crawford, H.C., King Jr., L.E., Mudgett, J., and Matrisian, L.M. 2004. A protective role for matrix metalloproteinase-3 in squamous cell carcinoma. Cancer Res. 64: 6965-6972.

Mignatti, P., Robbins, E., and Rifkin, D.B. 1986. Tumor invasion through the human amniotic membrane: Requirement for a proteinase cascade. Cell 47: 487-498.

Mott, J.D., Khalifah, R.G., Nagase, H., Shield III, C.F., Hudson, J.K., and Hudson, B.G. 1997. Nonenzymatic glycation of type IV collagen and matrix metalloproteinase susceptibility. Kidney Int. 52: 1302-1312.

Overall, C.M. and Kleifeld, O. 2006. Validating matrix metalloproteinases as drug targets and anti-targets for cancer therapy. Nat. Rev. Cancer 6: 227-239.

Pei, D. and Weiss, S.J. 1995. Furin-dependent intracellular activation of the human stromelysin-3 zymogen. Nature 375: 244-247.

Pelman, G.W., Morrison, C.J., and Overall, C.M. 2005. Pivotal molecular determinants of peptidic and collagen triple helicase activities reside in the $\mathrm{S}_{3}{ }^{\prime}$ subsite of matrix metalloproteinase 8 (MMP-8). J. Biol. Chem. 280: 2370-2377.

Poschl, E., Schlotzer-Schrehardt, U., Brachvogel, B., Saito, K., Ninomiya, Y., and Mayer, U. 2004. Collagen IV is essential for basement membrane stability but dispensable for initiation of its assembly during early development. Development 131: 1619-1628.

Puente, X.S., Sanchez, L.M., Overall, C.M., and Lopez-Otin, C. 2003. Human and mouse proteases: A comparative genomic approach. Nat. Rev. Genet. 4: 544-558.

Radisky, D.C., Levy, D.D., Littlepage, L.E., Liu, H., Nelson, C.M., Fata, J.E., Leake, D., Godden, E.L., Albertson, D.G., Nieto, M.A., et al. 2005. Rac1b and reactive oxygen species mediate MMP-3-induced EMT and genomic instability. $\mathrm{Na}$ ture 436: 123-127.

Rosenthal, E.L., Johnson, T.M., Allen, E.D., Apel, I.J., Punturieri, A., and Weiss, S.J. 1998. Role of the plasminogen activator and matrix metalloproteinase systems in epidermal growth factor- and scatter factor-stimulated invasion of carcinoma cells. Cancer Res. 58: 5221-5230.

Sabeh, F., Ota, I., Holmbeck, K., Birkedal-Hansen, H., Soloway, P., Balbin, M., Lopez-Otin, C., Shapiro, S., Inada, M., Krane, S., et al. 2004. Tumor cell traffic through the extracellular matrix is controlled by the membrane-anchored collagenase, MT1-MMP. J. Cell Biol. 167: 769-781.

Saffarian, S., Collier, I.E., Marmer, B.L., Elson, E.L., and Goldberg, G. 2004. Interstitial collagenase is a Brownian ratchet driven by proteolysis of collagen. Science 306: 108-111.

Sherwood, D.R. 2006. Cell invasion through basement membranes: An anchor of understanding. Trends Cell Biol. 16: 250-256.

Sherwood, D.R., Butler, J.A., Kramer, J.M., and Sternberg, P.W. 2005. FOS-1 promotes basement-membrane removal during anchor-cell invasion in C. elegans. Cell 121: 951-962.

Tam, E.M., Moore, T.R., Butler, G.S., and Overall, C.M. 2004. Characterization of the distinct collagen binding, helicase and cleavage mechanisms of matrix metalloproteinase 2 and 14 (gelatinase A and MT1-MMP). J. Biol. Chem. 279: 4333643344.

Than, M.E., Bourenkov, G.P., Henrich, S., Mann, K., and Bode, 
Hotary et al.

W. 2005. The NC1 dimer of human placental basement membrane collagen IV: Does a covalent crosslink exist? Biol. Chem. 386: 759-766.

Ueno, H., Nakamura, H., Inoue, M., Imai, K., Noguchi, M., Sato, H., Seiki, M., and Okada, Y. 1997. Expression and tissue localization of membrane-types 1,2, and 3 matrix metalloproteinases in human invasive breast carcinomas. Cancer Res. 57: 2055-2060.

Vanacore, R.M., Friedman, D.B., Ham, A.L., Sundaramoorthy, M., and Hudson, B.G. 2005. Identification of S-hydroxylysylmethionine as the covalent cross-link of the noncollagenous (NC1) hexamer of the $\alpha 1 \alpha 1 \alpha 2$ collagen IV network. J. Biol. Chem. 280: 29300-29310.

Wada, K., Sato, H., Kinoh, H., Kajita, M., Yamamoto, H., and Seiki, M. 1998. Cloning of three Caenorhabditis elegans genes potentially encoding novel matrix metalloproteinases. Gene 211: 57-62.

Wang, P., Nie, J., and Pei, D. 2004. The hemopexin domain of membrane-type matrix metalloproteinase-1 (MT1-MMP) is not required for its activation of proMMP2 on cell surface but is essential for MT1-MMP-mediated invasion in threedimensional type I collagen. I. Biol. Chem. 279: 51148 51155.

Weiss, S.J. 1989. Tissue destruction by neutrophils. N. Engl. J. Med. 320: 365-376.

Witz, C.A., Montoya-Rodriguez, I.A., Cho, S., Centonze, V.E., Bonewald, L.F., and Schenken, R.S. 2001. Composition of the extracellular matrix of the peritoneum. J. Soc. Gynecol. Investig. 8: 299-304.

Xu, J., Rodriguez, D., Petitclerc, E., Kim, J.J., Hangai, M., Yuen, S.M., Davis, G.E., and Brooks, P.C. 2001. Proteolytic exposure of a cryptic site within collagen type IV is required for angiogenesis and tumor growth in vivo. J. Cell Biol. 154: 1069-1079.

Yana, I. and Weiss, S.J. 2000. Regulation of membrane type-1 matrix metalloproteinase activation by proprotein convertase. Mol. Biol. Cell 11: 2387-2401. 


\section{Erratum}

Genes \& Development 20: 2673-2686 (2006)

A cancer cell metalloprotease triad regulates the basement membrane transmigration program

Kevin Hotary, Xiao-Yan Li, Edward Allen, Susan L. Stevens, and Stephen J. Weiss

The authors of the above-mentioned paper have discovered an error in the nucleotide sequence reported in the Materials and Methods section on page 2684, left column, third paragraph under the heading SiRNA

Electroporation. The sequence for MT2-MMP on lines 3 and 4 should read

"(5'-AACAACCACCATCTGACCTTT-3'; nucleotides 418-438)." This correction alters none of the data or conclusions. 


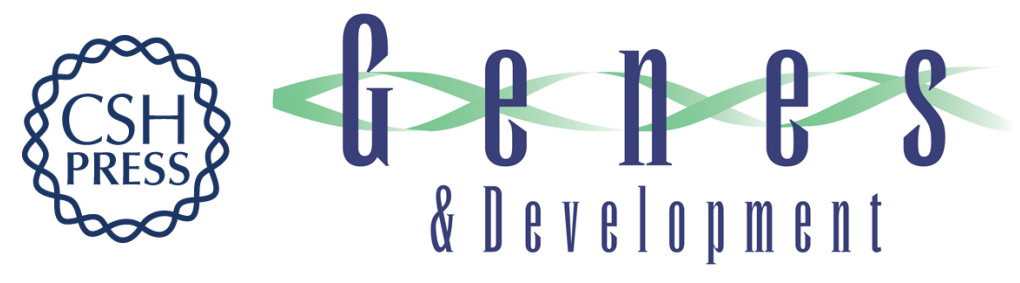

\section{A cancer cell metalloprotease triad regulates the basement membrane transmigration program}

Kevin Hotary, Xiao-Yan Li, Edward Allen, et al.

Genes Dev. 2006, 20: originally published online September 18, 2006

Access the most recent version at doi:10.1101/gad.1451806

\section{Supplemental http://genesdev.cshlp.org/content/suppl/2006/09/19/gad.1451806.DC1 Material}

Related Content

Erratum

Genes Dev. May , 2007 21: 1139

References This article cites 55 articles, 25 of which can be accessed free at: http://genesdev.cshlp.org/content/20/19/2673.full.html\#ref-list-1

Articles cited in:

http://genesdev.cshlp.org/content/20/19/2673.full.html\#related-urls

\section{License}

Email Alerting

Service

Receive free email alerts when new articles cite this article - sign up in the box at the top right corner of the article or click here.

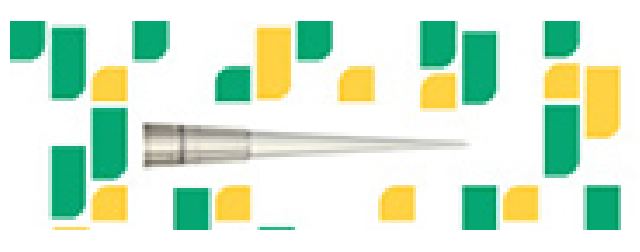

Focused on your science. 